\title{
III Colóquio Espaço e Economia [UERJ, 2019] - 2.a Parte
}

Floriano José Godinho de Oliveira, Leandro Dias de Oliveira, Roberto Moraes Pessanha and Regina Helena Tunes

\section{OpenEdition \\ 12 Journals}

\section{Electronic version}

URL: http://journals.openedition.org/espacoeconomia/8533

DOI: $10.4000 /$ espacoeconomia.8533

ISSN: 2317-7837

\section{Publisher}

Núcleo de Pesquisa Espaço \& Economia

\section{Electronic reference}

Floriano José Godinho de Oliveira, Leandro Dias de Oliveira, Roberto Moraes Pessanha and Regina Helena Tunes, « III Colóquio espaço e EConomia [UeRJ, 2019] - 2. a PARTE », Espaço e Economia [Online], 15 | 2019, Online since 03 November 2019, connection on 24 September 2020. URL : http:// journals.openedition.org/espacoeconomia/8533; DOI : https://doi.org/10.4000/espacoeconomia. 8533

This text was automatically generated on 24 September 2020 


\title{
III Colóquio Espaço e Economia [UERJ, 2019] - 2.. Parte
}

\author{
Floriano José Godinho de Oliveira, Leandro Dias de Oliveira, Roberto \\ Moraes Pessanha and Regina Helena Tunes
}

1 Espaço e Economia: Revista Brasileira de Geografia Econômica dedica sua 15. edição à publicização da segunda parte dos artigos apresentados no III Colóquio Espaço e Economia: Transformações no capitalismo mundial e a produção social do espaço: novos arranjos territoriais e a economia política do desenvolvimento, realizado na Universidade do Estado do Rio de Janeiro, entre os dias 10 e 12 de junho de 2019.

2 Assim, os treze textos que compõem a seção "Artigos" desta edição são oriundos das comunicações orais realizadas no decorrer do colóquio. Uma última edição especial de Espaço e Economia ainda contemplará os demais artigos aceitos, apresentados e revisados no decorrer do evento.

3 É importante reforçar, antes de mais, os agradecimentos pelo apoio da Fundação de Amparo à Pesquisa do Estado do Rio de Janeiro (Faperj), da Coordenação de Aperfeiçoamento de Pessoal de Nível Superior (Capes) e do Conselho Nacional de Desenvolvimento Científico e Tecnológico (CNPq), bem como destacar o papel institucional do Programa de Pós-Graduação em Políticas Públicas e Formação Humana (PPFH-UERJ), do Programa de Pós-Graduação em Geografia da UFRRJ (PPGGEO-UFRRJ), doPrograma de Pós-Graduação em Geografia da UERJ (PPGEO-UERJ) e do Instituto Federal de Educação, Ciência e Tecnologia Fluminense - Campos dos Goytacazes para a realização do evento.

4 Na seção seguinte, “Conexões”, destacamos contribuições importantes realizadas por pesquisadores da RELAEE - Rede Latino-Americana Espaço e Economia em outros periódicos de expressão. Na seção "Livros", três obras recém-lançadas são apresentadas como sugestões de leitura sobre debates importantes e caros ao periódico. Tais seções fortalecem o papel de Espaço e Economia: Revista Brasileira de Geografia Econômica como um portal para o campo da Geografia Econômica em seus diversos matizes. 